\title{
Sistem Infomasi Pengaduan Masyarakat Desa Sumberanyar Kecamatan Paiton Berbasis Android
}

\author{
Roisyatul Mutaqin*1, Anis Yusrotun N. ${ }^{2}$, Wahab Sya'roni ${ }^{3}$ \\ ${ }^{1,2,3}$ Program Studi Teknik Informatika, Fakultas Teknik, Universitas Nurul Jadid \\ Karanganyar Paiton Probolinggo \\ e-mail: *11 raisyaaurora1234@gmail.com, ${ }^{2}$ ayusrotun@gmail.com, ${ }^{3}$ wahab.syaroni@gmail.com
}

\begin{abstract}
Abstrak
Pelayanan publik merupakan hal penting yang harus diperhatikan dalam pembangunan suatu otonom daerah karena langsung diidentikkan dengan bantuan pemerintah selain itu sesuai dengan reformasi dasar di bidang pemerintahan. Akan tetapi pelayanan masyarakat yang ada di desa sumberanyar khususnya dalam hal pengaduan seperti pengaduan tentang bantuan sosial, infrastruktur dan pengaduan yang lain masih dilakukan secara fisik dan belum menggunakan kerangka kerja yang memuaskan, dimana masyarakat desa sumberanyar perlu datang ke kantor desa untuk menyampaikan aspirasi dan pengaduan serta di desa sumberanyar belum ada sarana untuk menyampaikan aspirasi dan pengaduan sehingga aspirasi atau pengaduan masyarakat belum bisa dilakukan secara maksimal dan data tentang pengaduan masyarakat tidak terdokumentasi dengan baik. Oleh karena itu penting untuk meliliki aplikasi yang bisa memudahkan masyarakat dalam melakukan pengaduan, sistem infomasi pelayanan masyarakat desa sumberanyar kecamatan paiton berbasis android adalah solusi untuk mengatasi permasalahan yang telah diuraikan. Aplikasi ini dibangun dengan menggunakan model SLDC (Software Development Life Cycle) Waterfall, dari hasil penelitian ini disimpulkan bahwa aplikasi tersebut sangat layak digunakan oleh masyarakat untuk melakukan pengaduan dan penyampaian aspirasi serta semua fitur pada aplikasi bisa digunakan dengan baik.
\end{abstract}

Kata kunci: Pelayanan, Waterfall, pengaduan.

\begin{abstract}
Public service is an important thing that must be considered in the development of an autonomous region, because it is directly related to the welfare of the community as well as in accordance with basic reforms in the field of government. However, community services in the Sumberanyar village, especially in terms of complaints such as complaints about social assistance, infrastructure and other complaints are still done manually and have not used an adequate system, where the Sumberanyar village community needs to come to the village office to convey their aspirations and complaints and in Sumberanyar village there is no means to convey aspirations and complaints so that public aspirations or complaints cannot be carried out optimally and data on community complaints are not well documented. Therefore, it is necessary to have an application that can make it easier for the community to make complaints, the Android-based information system for community service in Sumberanyar village, Paiton district, is a solution to overcome the problems that have been described. This application was built using the Waterfall SLDC (Software Development Life Cycle) model, from the results of this study it was concluded that the application is very suitable for use by the public to make complaints and convey aspirations and all features in the application can be used properly.
\end{abstract}

Keywords: Service, Waterfall, complaint. 


\section{PENDAHULUAN}

Berbicara tentang pelayanan publik, Pemerintah memainkan peran dan tugas yang sangat penting di dalamnya menawarkan bantuan yang luar biasa bagi masyarakat/daerah setempat, apalagi mengenai pelayanan publik saat ini cenderung "jalan ditempat". Sebagaimana yang diamanatkan dalam (Undang-Undang pasal 1 Nomor 25 tahun 2009) Pelayanan Publik adalah suatu rencana tindakan atau gerakan berkenaan dengan pemenuhan kebutuhan dasar sesuai dengan kebebasan sosial setiap penduduk dan yang berupa suatu benda, bantuan administrasi dan manajerial yang diberikan oleh organisasi kepada publik.

Desa Sumberanyar merupakan desa yang terletak kecamatan Paiton - Probolinggo, nama sumberanyar sendiri memiliki sebuah arti yaitu sumber yang berarti mata air dan anyar menurut bahasa madura adalah baru. Sebagian besar warga desa sumberanyar memiliki mata pencaharian sebagai petani dan nelayan. Desa sumberanyar memiliki kantor desa yang terletak di pinggir jalan, yang digunakan oleh kepala desa dan aparatur desa untuk melakukan pelayanan publik atau pelayanan masyarakat. Menurut Sinambela dalam jurnalnya kata pelayanan berasal dari kata "service" yang berarti segala sesuatu yang diperlukan untuk membantu menyediakan sesuatu untuk pelayanan orang lain. Pada dasarnya tiap orang memerlukan pelayanan, apalagi dalam permasalahan yang ekstrim bisa dikatakan pelayanan tidak bisa dilepaskan dari kehidupan manusia. Tujuan dari pengaduan merupakan penyedia sistem, prosedur serta mekanisme supaya pengaduan ataupun keluhan dari seluruh pihak bisa tertangani dengan baik, sehingga tidak memunculkan kerancuan serta mengusik kelancaran aktivitas lembaga pemerintah [1].

Pelayanan publik ialah perihal yang wajib dicermati dalam pembangunan suatu otonom daerah, karena berkaitan langsung dengan kesejahteraan warga tidak hanya itu pula sesuai dengan reformasi dasar di bidang pemerintahan. Tujuan utama penyelenggaraan administrasi publik adalah melayani masyarakat. Pelayanan publik yang maksimal tercermin dari sumber daya yang mumpuni untuk melakukan dan menyelesaikan tugas yang telah ditetapkan [2]. Akan tetapi pelayanan masyarakat yang ada di desa sumberanyar khususnya dalam hal pengaduan seperti pengaduan tentang bantuan sosial, infrastruktur dan pengaduan yang lainnya masih dilakukan secara fisik dan belum menggunakan kerangka kerja yang memuaskan, dimana masyarakat desa sumberanyar perlu datang ke kantor desa untuk menyampaikan aspirasi dan pengaduan serta di desa sumberanyar belum ada sarana untuk menyampaikan aspirasi dan pengaduan sehingga aspirasi atau pengaduan masyarakat belum bisa dilakukan secara maksimal dan data tentang pengaduan masyarakat tidak terdokumentasi dengan baik. sistem adalah aktivitas yang digunakan untuk melihat sistem yang sudah berjalan, memahami seberapa baik sistem tersebut, dan kemudian mencatat persyaratan yang akan dipenuhi oleh sistem baru [3].

Penelitian pertama yang dilakukan oleh(Mohi \& Mahmud, 2018)dengan judul "Kualitas Pelayanan Publik di Desa Potanga Kecamatan Boliyohuto Kabupaten Gorontalo" yang melatar belakangi penelitian ini yaitu di bidang ekonomi, pelayanan publik yang buruk akan mengakibatkan turunnya investasi yang berakibat pada pemutusan hubungan kerja di industri dan tidak mampu menciptakan lapangan kerja baru, yang juga akan berdampak pada meningkatnya pengangguran. Tujuan dari penelitian ini adalah untuk mengetahui kualitas pelayanan publik di Desa Potanga Kecamatan Boliyohuto, dan hambatan dalam meningkatkan kualitas pelayanan public [4].

Penelitian selanjutnya yang dilakukan oleh(Ahmadi \& Juliansa, 2019), yang berjudul "Rancang Bangun Sistem Informasi Digital Layanan Administrasi Publik Desa Berbasis WEB Responsive" menjelaskan bahwa proses administrasi publik Desa Tanjung di Kabupaten Musi Rawas Kecamatan Muara Kelingi didasarkan pada kunjungan warga ke kantor desa, kemudian dilakukan pendataan identitas kependudukan, pencatatan kebutuhan masyarakat akan pelayanan publik yang dibutuhkan, dan tindak lanjut dari masyarakat perlu memberi tahu desa. Sistem atau 
aplikasi yang dibangun bisa membantu warga desa agar lebih mudah dalam melakukan proses pelayanan manajemen kependudukan khususnya bagi warga yang ini membuat surat lamaran secara digital, antara lain pengajuan KTP dan KK, akta nikah, akta kelahiran dan dokumen lainnya. [5].

Penelitian ketiga dilakukan oleh(Rohmatun et al., 2017), yang berjudul "Pengembangan Sistem Informasi Pengaduan Masyarakat Kabupaten Jepara Berbasis Web" menjelaskan bahwa Pemerintah Kabupaten Jepara sendiri sudah menerapkan suatu bentuk pengabdian kepada masyarakat, yaitu sistem yang melayani pendapat masyarakat dan menanggapi keluhan masyarakat. Namun sistem pengaduan tersebut belum optimal karena masih menggunakan email dalam proses pengelolaan pengaduan masyarakat. Kesimpulan dari penelitian ini adalah sistem dapat digunakan oleh masyarakat untuk mengadukan masalah, dan respon pemerintah dapat diperoleh melalui hak aksesnya. Sistem ini dapat memperoleh laporan atau file pengaduan, yang dapat digunakan oleh pemerintah untuk mengevaluasi proyek yang sedang berjalan [6].

Bersumber pada penjelasan di atas, hingga butuh adanya sistem yang bisa mempermudah masyarakat desa sumberanyar dalam menyampaikan aspirasi dan pengaduan. Sistem informasi adalah sistem yang terdiri dari kompone - komponen yang mengendalikan organisasi dalam mencapai suatu tujuan [7]. Sistem infomasi pelayanan masyarakat desa sumberanyar kecamatan paiton berbasis android adalah solusi untuk mengatasi permasalahan yang telah diuraikan. Aplikasi yang dibangun berbasis android, dimana Android adalah sistem operasi yang berbasis Linux untuk perangkat seluler, termasuk sistem operasi, middleware, dan aplikasi [8]. Diharapkan dengan melakukan penelitian ini dapat di ambil manfaat seperti memudahkan masyarakat desa sumberanyar dalam menyampaikan aspirasi dan pengaduan terutama tentang bantuan sosial, infrastruktur dan lainnya.

\section{METODE PENELITIAN}

Metode kualitatif digunakan dalam penelitian dan model SLDC waterfall, dengan tujuannya adalah untuk mengumpulkan data mengenai pelayanan publik di Desa Sumberanyar Kecamatan Paiton. Metode kualitatif adalah jenis penelitian dimana peneliti digunakan sebagai alat utama dan menggabungkan teknologi pengumpulan data. [9].

Model air terjun SDLC juga dikenal sebagai model siklus sekuensial linier atau klasik. Model air terjun menyediakan pendekatan aliran hidup perangkat lunak sekuensial dari tahap analisis kebutuhan sistem, desain sistem, pengkodean atau implementasi, pengujian atau testing, dan dukungan. [10]. Salah satu alasan menggunakan metode air terjun adalah karena tahapan yang dilakukan urut dan berkesinambungan, seperti layaknya sebuah air terjun. Di bawah ini adalah gambaran fase atau tahapan pada model waterfall ditunjukkan pada gambar 1 seperti dibawah ini [11]: 


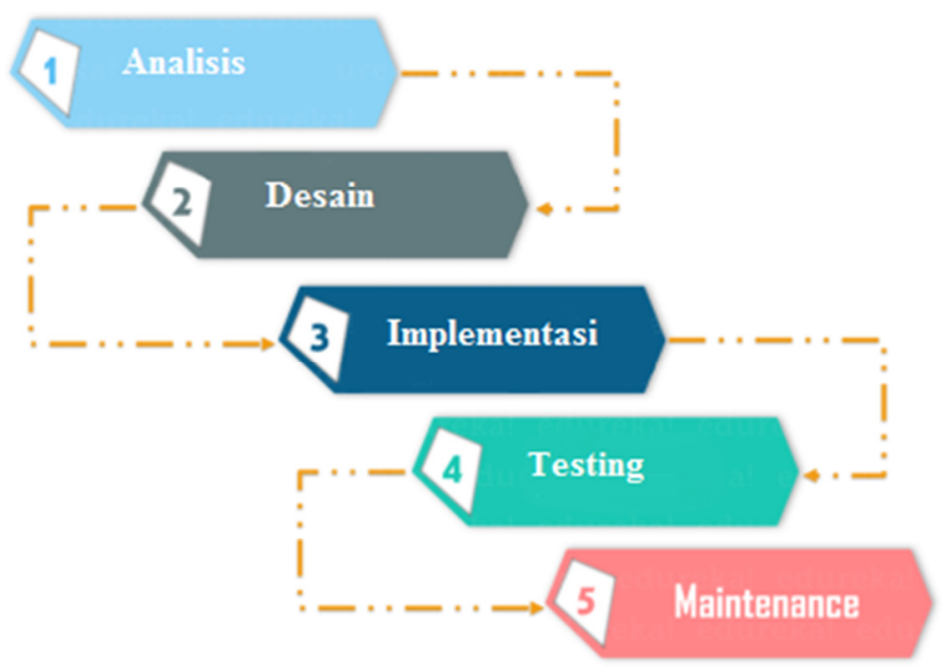

Gambar 1. Model Waterfall [11]

\subsection{Analisis}

Rekayasa Kebutuhan merupakan batasan sistem yang akan beroperasi dan dikembangkan dari proses membentuk layanan yang dibutuhkan masyarakat dari suatu sistem. Dalam proses analisis ini peneliti menggunakan observasi dan wawancara.

a. Obervasi

Observasi dilakukan untuk mengetahui dan mengidentifikasi kondisi pelayanan di kantor Desa Sumberanyar Kecamatan Paiton.

b. Wawancara

Wawancara dilaksanakan secara langsung dengan bapak Moh. Toha, S.Pd.I,Mm selaku kepala desa Sumberanyar Kecamatan Paiton. Wawancara dilakukan dengan maksud untuk mengetahui lebih lanjut tentang alur sistem pengaduan masyarakat yang sedang berjalan di kantor desa Sumberanyar. Adapun target draf wawancara seperti tabel 1:

Tabel 1. Wawancara

\begin{tabular}{|c|c|l|}
\hline No. & Tanggal & \multicolumn{1}{c|}{ Target } \\
\hline & & $\begin{array}{l}\text { 1. } \\
\text { Seperti apa proses pelayanan di desa sumberanyar } \\
\text { khusunya tentang pengaduan? }\end{array}$ \\
& & $\begin{array}{l}\text { 2. } \\
\text { Apa saja yang pengaduan masyarakat? }\end{array}$ \\
& 15 Maret 2021 & $\begin{array}{l}\text { Bagaimana proses dalam menanggapi pengaduan } \\
\text { masyarakat? }\end{array}$ \\
& & \begin{tabular}{l} 
4. $\begin{array}{l}\text { Bagaimana harapan anda tentang sebuah aplikasi } \\
\text { untuk mempermudah dalam proses pengaduan } \\
\text { masyarakat? }\end{array}$ \\
\hline
\end{tabular} \\
\hline
\end{tabular}

\subsection{Desain}

Pada tahap ini peneliti membuart rancangan sistem yang akan digunakan dalam menciptakan aplikasi. Yang dijadikan bahan pertimbangan dalam perancangan adalah hasil dari analisa kebutuhan sistem. Dalam penelitian terdapat beberapa tahapan yang akan dilakukan, yaitu: Flowchart, Data Flow Diagram (DFD). 


\subsection{Implementasi}

Setelah tahap desain dari aplikasi berhasil dibuat, proses selanjutnya adalah mengimplementasikan desain yang telah dibuat menjadi kode program. Dalam penelitian ini di implementasikan pada perangkat android dan menggunakan java sebagai bahasa pemrograman. Sedangkan $M Y S Q L$ digunakan sebagai basis data.

\subsection{Testing atau Pengujian}

Dalam metode waterfall tahapan terpentingnya adalah melakukan pengujian. Tanpa pengujian, aplikasi yang dibuat tidak akan diketahui apakah aplikasi telah sesuai harapan dan apakah menjadi solusi dari permaslahan yang ada. Dalam pengujian sistem akan dihasilkan sebuah kesuksesan dan kesalahan dalam bentuk tabel uji.

a. Pengujian internal (BlackBox)

Setelah tahap pengujian selesai dan aplikasi yang dibuat telah sesuai harapan maka tahap berikutnya adalah menerapkan aplikasi tersebut. Dan dilanjutkan dengan melakukan perawatan terhadap aplikasi tersebut. Berikut tabel pengujian Black Box seperti tabel 2:

Tabel 2. Pengujian Internal

\begin{tabular}{|c|c|c|c|c|c|}
\hline \multirow{2}{*}{ No. } & \multirow{2}{*}{ Unit Uji } & \multirow{2}{*}{$\begin{array}{l}\text { Masukan/ } \\
\text { Kondisi }\end{array}$} & \multirow{2}{*}{ Hasil yang diharapkan } & \multicolumn{2}{|c|}{ Kesesuaian } \\
\hline & & & & $\mathrm{Ya}$ & Tidak \\
\hline \multirow[t]{2}{*}{1} & \multirow[t]{2}{*}{ Login } & \multirow[t]{2}{*}{$\begin{array}{l}\text { Akses } \\
\text { untuk } \\
\text { menuju ke } \\
\text { dashboard }\end{array}$} & $\begin{array}{l}\text { - Jika nik dan password } \\
\text { sesuai maka program akan } \\
\text { melanjutkan ke menu } \\
\text { utama. }\end{array}$ & & \\
\hline & & & $\begin{array}{lrr}\text { - Jika tidak } & \text { sesuai } & \text { maka } \\
\text { program } & \text { tidak } & \text { akan } \\
\text { melanjutkan } & \text { ke } & \text { menu } \\
\text { utama. } & & \\
\end{array}$ & & \\
\hline \multirow[t]{3}{*}{2} & \multirow[t]{3}{*}{ Dashboard } & Profil & $\begin{array}{l}\text { - Menampilkan data } \\
\text { masyarakat yang berhasil } \\
\text { login }\end{array}$ & & \\
\hline & & Pengaduan & $\begin{array}{ll}\text { - Menampilkan form } & \text { formaduan yang akan } \\
\text { pengaduan } \\
\text { dikirim ke aparature desa. }\end{array}$ & & \\
\hline & & Hisroty & $\begin{array}{ll}\text { - } & \text { Menampilkan } \\
\text { pengaduan dari masyarakat }\end{array}$ & & \\
\hline 3 & Profil & $\begin{array}{l}\text { Ganti } \\
\text { Password }\end{array}$ & $\begin{array}{l}\text { Menampilkan Form untuk } \\
\text { mengganti password }\end{array}$ & & \\
\hline 4 & Log Out & $\begin{array}{l}\text { Akses } \\
\text { untuk } \\
\text { menutup } \\
\text { program }\end{array}$ & $\begin{array}{l}\text { - Dapat menutup program } \\
\text { (kembali ke menu login) }\end{array}$ & & \\
\hline
\end{tabular}

\subsection{Perawatan (Maintenance)}

Setelah dikatakan layak untuk digunakan dan sistem telah melewati tahapan pengujian maka tahapan selanjutnya adalah melakukan maintenance. Melakukan melakukan instalasi sistem informasi pengaduan masyarakat desa sumberanyar kecamatan paiton berbasis android sebagai langkah pertama dalam melakukan maintenance. Dalam penelitian ini, sistem informasi pengaduan yang telah diciptakan akan di upload dan dipasang pada server yang telah disediakan oleh desa sumberanyar. 


\section{HASIL DAN PEMBAHASAN}

Peneliti melakukan Obervasi, Wawancara dan Studi Pustaka guna untuk mengumpulkan data. Hasil dari pengumpulan data yang peneliti lakukan dijelaskan sebagai berikut :

\subsection{Analisis}

\section{a. Observasi}

Observasi dilakukan dengan mengamati proses pengaduan mengenai pelayanan masyarakat tentang aspirasi pelayanan yang dilakukan saat ini di Kantor Desa Sumberanyar Kecamatan Paiton. Dari hasil observasi yang peneliti telah dilakukan, diketahui bahwa pengaduan atau penyampaian mengenai aspirasi yang ada di desa Sumberanyar masih menerapkan cara manual yaitu warga datang ke kantor desa kemudian menemui kepala desa dan aparatur desa demi mengajukan pengaduan apa saja yang ingin di adukan. Sehingga para warga desa sumberanyar masih kesulitan dengan adanya sistem yang saat ini dilakukan.

b. Wawancara

Salah satu Teknik dalam melakukan proses pengumpulan data dengan cara peneliti bertanya langsung kepada pihak terkait disebut wawancara. Wawancara dilaksanakan secara langsung dengan bapak Moh. Toha, S.Pd.I,Mm selaku kepala desa Sumberanyar Kecamatan Paiton. Wawancara dilakukan dengan maksud untuk mengetahui lebih lanjut tentang alur sistem pengaduan masyarakat yang sedang berjalan di kantor desa Sumberanyar. Dari wawancara yang dilakukan dapat disimpulkan bahwa sistem pengaduan yang ada di desa sumberanyar saat ini masih menggunakan cara manual dan juga mengenai laporan yang disampaikan oleh setiap aparatur harus mengumpulkan warganya terlebih dahulu agar semua mengetahui tentang aspirasi apa saja yang masyarakat keluhkan. Dengan hasil laporan mengenai aspirasi tentang pelayanan masyarakat yang disampaikan dengan menggunakan surat.

\subsection{Desain}

Setelah melakukan tahap analisa kebutuhan maka selanjutnya peneliti membuat rancangan desain sistem dari data yang telah diperoleh pada tahap analisa kebutuhan agar dapat diimplementasikan menjadi program dalam tahap selanjutnya tahapan-tahapan desain ini meliput alur sistem (Flowchart) seperti flowchart sistem lama dan flowchart sistem baru.

a. Bagan Alur Sitem (Flowchat)

flowchart adalah suatu prosedur atau algoritma yang digunakan untuk menyelesaikan masalah dengan representasi secara simbolik, dalam analisa masalah akan membuat pengguna mudah dalam melakukan koreksi bagian yang terlupakan dengan menggunakan flowchart, disamping itu flowchart juga dijadikan sebagai fasilitas dalam berkomunikasi dalam tim suatu proyek dan antara pemrogram yang bekerja maka dibuatlah flowchart sistem lama dan flowchart sistem baru yang peneliti usulkan agar perbedaan antara sistem yang sedang berjalan di Desa Sumberanyar Kecamatan Paiton dengan sistem baru yang di usulkan bisa lebih jelas dan lebih spesifik 
1) Flowchart Sistem Lama

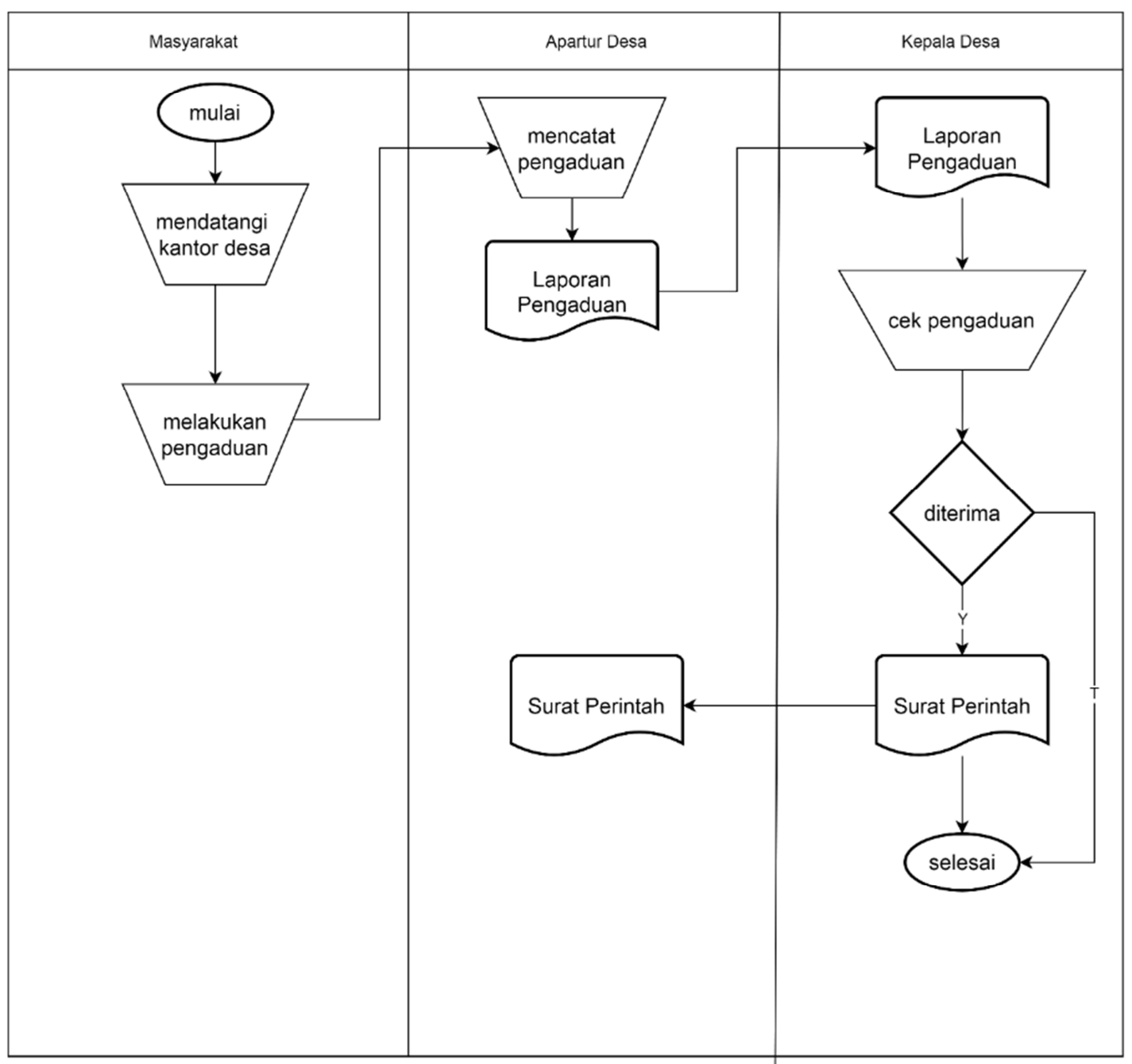

Gambar 2. Flowchart Sistem Lama 
2) Flowchart Sistem Baru

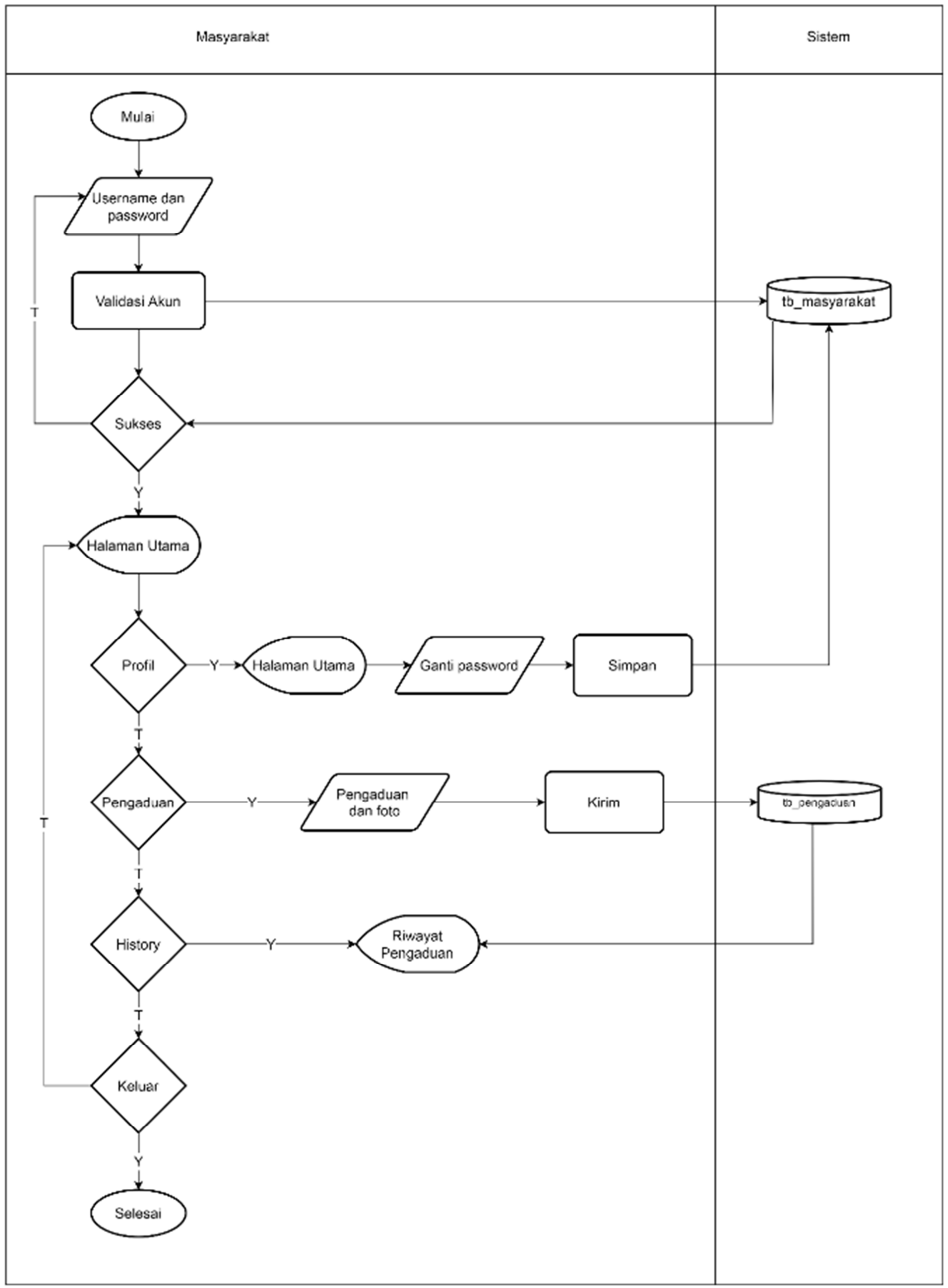

Gambar 3. Flowchart Sistem Lama 


\subsection{Implementasi}

a. Form login

Masyarakat yang akan menggunakan aplikasi ini dan harus login terlebih dulu sebelum menggunakan aplikasi ini.

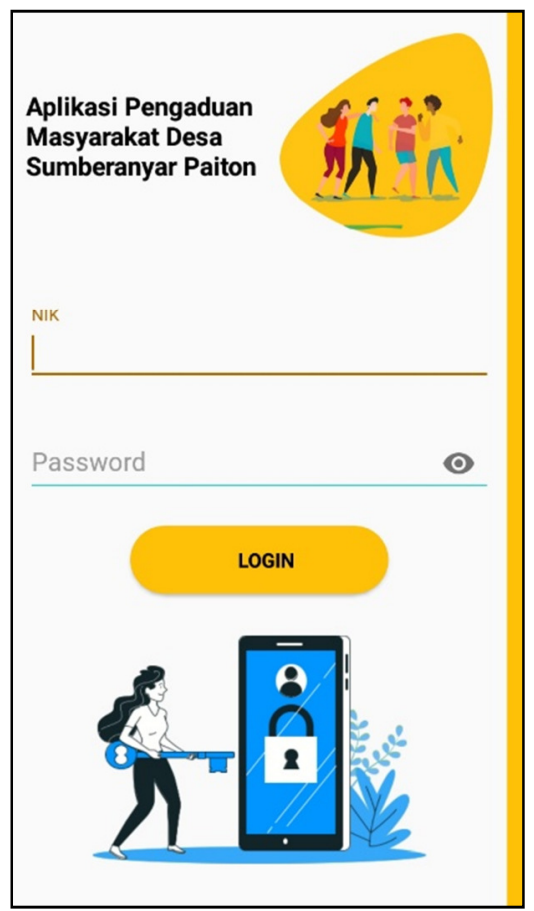

Gambar 4. Screenshot Form Login

b. Dashboard

Dashboard adalah form yang akan tampil jika login dari masyarakat sukses tapi jika gagal, masyarakat tidak akan masuk ke dashboard. Dashboard adalah form yang menampilkan fitur-fitur yang ada dalam sistem ini. 


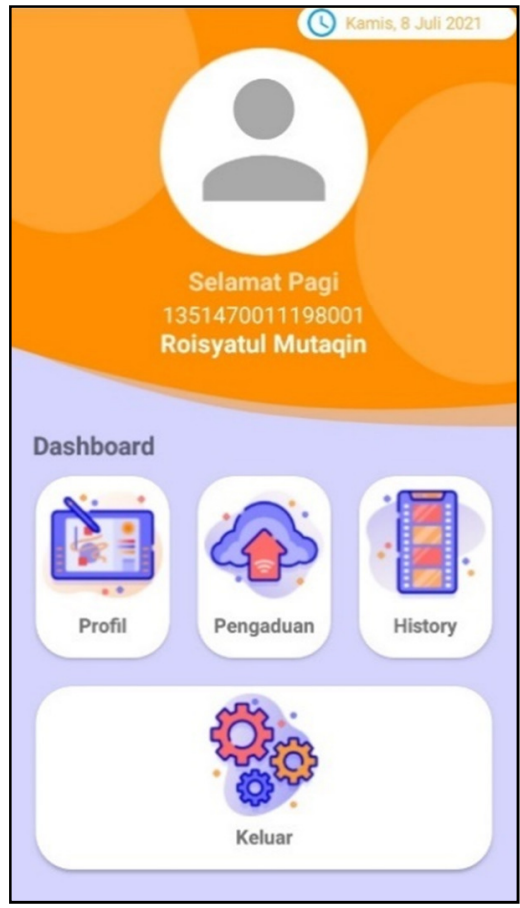

Gambar 5. Screenshot Dashboard

c. Form Pengaduan

Form pengaduan digunakan masyarakat untuk melakukan pengaduan atau aspirasi ke desa sumberanyar kecamatan paiton.

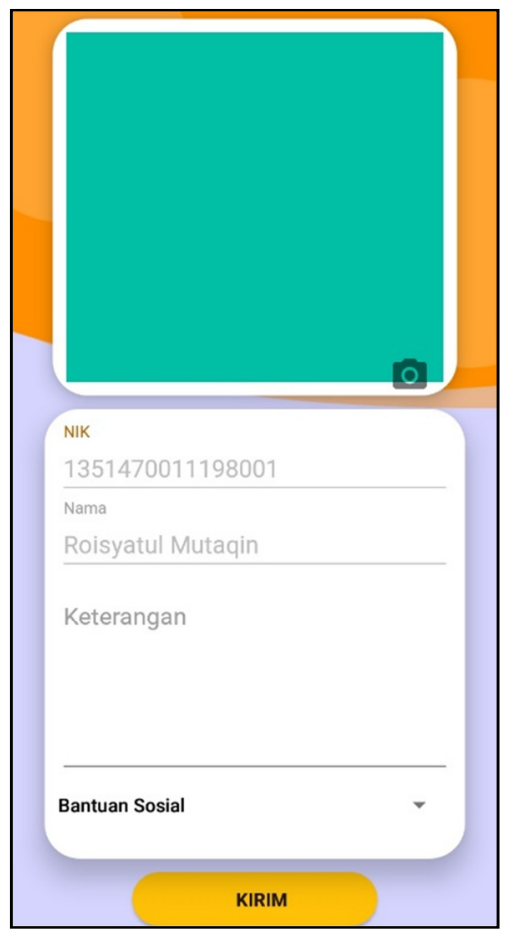

Gambar 7. Screenshot Form Pengaduan

Mutaqin, et., al [Sistem Infomasi Pengaduan Masyarakat Desa Sumberanyar Kecamatan Paiton Berbasis Android] 
d. Riwayat Pengaduan

Riwayat pengaduan digunakan oleh masyarakat untuk melihat hasil dari pengaduan yang dilakukan.

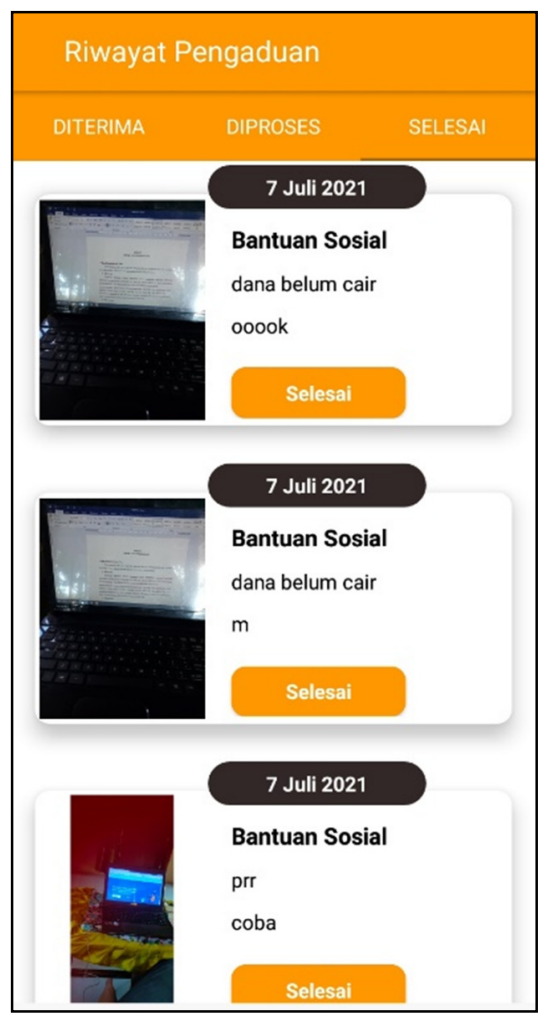

Gambar 8 Screenshot Riwayat Pengaduan

\subsection{Hasil Pengujian}

a. Pengujian Black Box

Pengujian internal atau black box program yang diuji oleh Masyarakat Desa Sumberanyar Kecamatan seperti yang ditunjukkan tabel 7 dibawah ini :

Tabel 7. Pengujian Internal Blackbox

\begin{tabular}{|c|c|c|c|c|c|}
\hline \multirow{2}{*}{ No. } & \multirow{2}{*}{ Unit Uji } & \multirow{2}{*}{$\begin{array}{l}\text { Masukan/ } \\
\text { Kondisi }\end{array}$} & \multirow{2}{*}{ Hasil yang diharapkan } & \multicolumn{2}{|c|}{ Kesesuaian } \\
\hline & & & & $\mathrm{Ya}$ & Tidak \\
\hline \multirow[t]{2}{*}{1} & \multirow[t]{2}{*}{ Login } & \multirow{2}{*}{$\begin{array}{l}\text { Akses } \\
\text { untuk } \\
\text { menuju ke } \\
\text { dashboard }\end{array}$} & $\begin{array}{l}\text { - Jika nik dan password sesuai } \\
\text { maka program akan } \\
\text { melanjutkan ke menu utama. }\end{array}$ & $\checkmark$ & \\
\hline & & & $\begin{array}{l}\text { - Jika tidak sesuai maka program } \\
\text { tidak akan melanjutkan ke } \\
\text { menu utama. }\end{array}$ & $\checkmark$ & \\
\hline \multirow[t]{3}{*}{2} & \multirow[t]{3}{*}{ Dashboard } & Profil & $\begin{array}{l}\text { - Menampilkan data masyarakat } \\
\text { yang berhasil login }\end{array}$ & $\checkmark$ & \\
\hline & & Pengaduan & $\begin{array}{l}\text { - Menampilkan form pengaduan } \\
\text { yang akan dikirim ke aparature } \\
\text { desa. }\end{array}$ & $\checkmark$ & \\
\hline & & Hisroty & $\begin{array}{l}\text { - Menampilkan hasil pengaduan } \\
\text { dari masyarakat }\end{array}$ & $\checkmark$ & \\
\hline
\end{tabular}




\begin{tabular}{|l|l|l|l|l|l|}
\hline 3 & Profil & $\begin{array}{l}\text { Ganti } \\
\text { Password }\end{array}$ & $\begin{array}{l}\text { - Menampilkan Form untuk } \\
\text { mengganti password }\end{array}$ & $\checkmark$ & \\
\hline 4 & Log Out & $\begin{array}{l}\text { Akses } \\
\text { untuk } \\
\text { menutup } \\
\text { program }\end{array}$ & $\begin{array}{l}\text { Dapat menutup program } \\
\text { (kembali ke menu login) }\end{array}$ & $\checkmark$ & \\
\hline
\end{tabular}

\section{KESIMPULAN}

Setelah melakukan penelitian serta membahas hasil penelitian secara tuntas sehingga tercipta Sistem Informasi Pengaduan Masyarakat Desa Sumberanyar Kecamatan Paiton Berbasis Android, maka kesimpulan dari penelitian ini adalah bahwa aplikasi yang telah dibangun dapat membantu dan mempermudah masyarakat khususnya desa sumberanyar kecamatan paiton dalam melakukan pengaduan dan penyampaian aspirasi. Semua fitur pada aplikasi dapat digunakan dengan baik, sehingga masyarakat bisa melakukan pengaduan dan penyampaian aspirasi masyarakat.

\section{SARAN}

Adapun beberapa hal ini yang dapat dijadikan bahan evaluasi untuk pengembangan sistem kedepannya :

1. Perlu adanya penambahan fitur lokasi, sehingga masyarakat bisa lebih akurat dalam membrikan informasi pengaduan.

2. Perlunya penambahan fitur informasi dari desa, sehingga masyarakat desa sumberanyar mendapatkan informasi lebih cepat dan akurat.

\section{UCAPAN TERIMA KASIH}

Terimakasih penulis sampaikan kepada bapak Moh. Toha, S.Pd.I, Mm selaku kepala desa Sumberanyar Kecamatan Paiton yang telah memperbolehkan penulis melakukan penelitian dan uji sistem di kantor desa sumberanyar kecamatan paiton.

\section{DAFTAR PUSTAKA}

[1] Firmansyah, C., \& Tohir, C. 2018, Sistem Layanan Pengaduan Masyarakat Lingkup Desa GunungTanjung Berbasis Web dan SMS Gateway Dengan Metode Antrian Fifo 1, Jurnal Manajemen dan Teknik Informatika (JUMANTAKA), 01(01), 201-210. http://jurnal.stmik-dci.ac.id/index.php/jumantaka/article/download/283/371

[2] Mohi, W. K., \& Mahmud, I. 2018, Kualitas Pelayanan Publik di Desa Potanga Kecamatan Boliyohuto Kabupaten Gorontalo, Publik: (Jurnal Ilmu Administrasi), 6(2).

[3] Kuswoyo, A., Akuntansi, K., Akuntansi, K., Diagram, C., Collections, A., \& Lampung, B. 2021. Pengembangan Aplikasi Penjualan Barang pada Butik Agris, 21(1), 530-536. 
[4] Mohi, W. K., \& Mahmud, I. 2018, Kualitas Pelayanan Publik di Desa Potanga Kecamatan Boliyohuto Kabupaten Gorontalo, Publik: (Jurnal Ilmu Administrasi), 6(2), 102. https://doi.org/10.31314/pjia.6.2.102-110.2017

[5] Ahmadi, A., \& Juliansa, H. 2019, Rancang Bangun Sistem Informasi Digital Layanan Administrasi Publik Desa Berbasis WEB Responsive, Jurnal Ilmiah Informatika Global, 10(1). https://doi.org/10.36982/jig.v10i1.731

[6] Rohmatun, S., Widihastuti, I., \& Khosyi'in, M. 2017, Pengembangan Sistem Informasi Pengaduan Masyarakat Kabupaten Jepara Berbasis Web, TRANSISTOR Elektro dan Informatika, 2(2), 111-123.

[7] Firmansyah, Y., \& Pitriani. 2017, Penerapan Metode SDLC Waterfall Dalam Pembuatan Aplikasi Pelayanan Anggota pada CV Duta Usaha Bersama Pontianak. Jurnal Bianglala Informatika, 5(2), 53-61. https://ejournal.bsi.ac.id/ejurnal/index.php/Bianglala/article/view/2703/1813

[8] Rahmayuda, T., \& Kurniadi, D. 2019, Perancangan Aplikasi Mobile Sebagai Media Promosi Tempat Kost dan Fasisiltas Pendukung Berbasis Android, VoteTEKNIKA: Jurnal Vocational Teknik Elektronika Dan Informatika, 7(2), 8-19.

[9] Yusanto, Y. 2020, Ragam Pendekatan Penelitian Kualitatif, Journal of Scientific Communication (JSc), 1(1), 1-13. https://doi.org/10.31506/jsc.v1i1.7764

[10] Tabrani, M. 2018, Penerapan Metode Waterfall pada Sistem Informasi Inventori PT. Pangan Sehat Sejahtera, Jurnal Inkofar, 1(2),30-40.

[11] Rizaldi. 2017, Penerapan Waterfall Dalam Membangun Sistem Informasi Pengolahan Data Pelaksanaan Konstruksi Pembangunan Jalan. IV(1).

[12] Maryuliana, Subroto, I. M. I., \& Haviana, S. F. C. 2016, Sistem Informasi Angket Pengukuran Skala Kebutuhan Materi Pembelajaran Tambahan Sebagai Pendukung Pengambilan Keputusan Di Sekolah Menengah Atas Menggunakan Skala Likert. Jurnal Transistor Elektro dan Informatika, 1(2), 1-12. 